\title{
Design and Development of Cultural and Creative Products in Jiujiang Museum
}

\author{
Hong Zhang
}

\author{
Suan Sunandha Rajabhat University \\ *11180557@qq.com
}

\begin{abstract}
In recent years, the public has developed a strong interest in visiting museums, and the museum tourism boom is gradually rising in major cities in China. Under this background, museums have changed their previous academic attitude and become closer to the needs of the public. Various forms of museum cultural and creative products have become popular. In the past, museums focused on displaying cultural relics to teach history and culture, reflecting the social education function of museums. Some western developed countries began to pay attention to the design and development of museum cultural and creative products decades ago, and achieved good results. However, the cultural and creative products of Chinese museums are still in a relatively backward state, and there are still many shortcomings in the process of design and development. Museums should change the single way of cultural communication in the past, carry out social education and cultural communication with novel cultural and creative products, and create unique cultural brands. Based on this, this paper explores and analyzes the design and development of cultural and creative products in Jiujiang Museum.
\end{abstract}

Keywords: Jiujiang City; Museum; cultural and creative products; design and development

\section{INTRODUCTION}

With the development of the times, museums, as cultural business cards of urban development, tell more and more tourists about urban history. In the process of visiting the museum, people are used to taking souvenirs as collections. Cultural and creative products of the museum contain many elements such as culture and emotion, which can meet the needs of visitors. Cultural and creative products are the embodiment of cultural inheritance, which can help the public improve their cultural character. Jiujiang Museum is a comprehensive museum with 5,173 pieces of cultural relics, including 1,800 pieces of precious collections, which are regularly held for exhibitions and academic discussions. However, there are few cultural and creative products in Jiujiang Museum, the theme is not targeted, and the product expression technique is single. The design of museum cultural and creative products must be different from general tourism products, and should carry relevant cultural information to meet the cultural experience of tourists. Therefore, the core principle of Jiujiang Museum should extract relevant elements from the collected cultural relics, creatively use regional cultural symbols, and enhance public satisfaction.

\section{CONCEPTUAL ANALYSIS OF MUSEUM CULTURAL AND CREATIVE PRODUCTS}

At present, the museum cultural industry at home and abroad is developing rapidly, and the design of cultural and creative products is constantly updated and iterated. However, there is no unified definition of museum cultural and creative products in academic circles [1]. As far as academic expression is concerned, it can be divided into three categories: museum cultural and creative products, museum cultural products and museum cultural derivatives. What they have in common is that they all focus on the cultural level of museums, that is, cultural derivatives. Therefore, museum cultural and creative products can basically be defined as the products with cultural connotations produced by refining, re-creating and designing museum cultural elements, which can show the unique charm of regional culture. 


\section{TYPE ANALYSIS OF CULTURAL AND CREATIVE PRODUCTS IN JIUJIANG MUSEUM}

At present, the cultural and creative products of Jiujiang Museum can be roughly divided into the following two types. One is the replica of cultural relics in the museum. Among the cultural and creative products of museums, cultural relics replication can effectively play the role of cultural communication, and generally, modern scientific and technological means are used to replicate cultural relics, such as 3D printing technology. For this kind of products, most of them are derivatives of cultural relics, with less functional functions, and most of them are ornaments to meet the needs of some high-end people, and then get spiritual or material satisfaction [2]. The other is original products. This kind of product is mainly an integrated design of various elements, with high originality. It is also an important expression of museum cultural and creative products. These products can not only meet the needs of mass consumers, but also effectively convey history and culture [3]. For example, in Jiujiang Museum's "Yanshui Pavilion Couplet Bookmark", Yanshui Pavilion, as one of the famous cultural tourist attractions in Jiujiang City, is a place for literati and poets in past dynasties, and there are many famous couplets in the pavilion. The Yanshui Pavilion Couplet Bookmark is carved by brass wire drawing laser, which not only has practical characteristics, but also can greatly meet the ornamental needs of consumers.

\section{DESIGN PRINCIPLES OF CULTURAL AND CREATIVE PRODUCTS IN JIUJIANG MUSEUM}

\subsection{Originality}

Through the change of thinking, we can give a new definition to products in the market. In order to effectively promote products in the market, innovative design thinking is the inevitable trend of cultural and creative product development. The innovation of cultural and creative products can not only change the concept of cultural communication, but also further enhance the market value of products, radiate more audiences and truly turn resources into attraction. Product image thinking refers to the visual analysis of a certain thing through visual observation by the audience in the cognitive process of the certain thing [4]. Different social groups will have different opinions in the process of recognizing the same thing. Originality is an important prerequisite for designing cultural and creative products. Product names, styles, signs, materials and a series of related designs should be designed according to the museum's own cultural characteristics to highlight the product design concept and personality. Creativity can induce a series of related brands, such as the symbolism of products, instead of simply copying and imitating. The main reasons for the similarity of many cultural and creative products in museums are the lack of original ideas, the fuzziness of cultural values and the excessive emphasis on economic interests. Only from the demand of "differentiated competition", through original brands, original symbols and other means, can we truly create personalized product images and promote the sustainable development of museum cultural and creative industries. Cultural and creative products, as a part of the overall image of Jiujiang Museum, should refine multicultural elements and design unique cultural and creative products from the museum's unique regional characteristics, historical allusions, cultural relics resources, architectural landscape and other aspects.

\subsection{Identity}

Identification is the basic function of cultural and creative products, the most effective way to distinguish product homogeneity, and it can give consumers a refreshing feeling. Image recognition of cultural and creative products in museums includes product concept recognition, product visual behavior and product behavior recognition [5]. Product concept recognition is the core value of cultural and creative products, which runs through the whole process of product design and development, and forms a unique brand effect through a series of product planning, publicity, promotion and marketing. Product visual behavior is the intuitive expression of cultural and creative products. Through the specific visual symbol communication, culture can be deeply branded into consumers' hearts. In the era of information flooding, in order to avoid absorbing invalid information, the public often pays attention to the selectivity of information. Cultural and creative product design has become an additional image label of museums, which can easily impress people. At present, the visual identification design and development of cultural and creative products is no longer just a simple graphic symbol, but a series of symbol combinations, including the museum's unique cultural symbols, regional features, architectural styles, etc., which are transformed into product identification elements to reflect the cultural connotation of the museum.

\subsection{Systematicness}

A system is not a simple combination of things, but a group of interrelated elements, which can achieve the goal as a whole. In the process of designing and developing museum cultural and creative products, cultural elements, interrelations and functional objectives are essential, and the specific design contents include product name, color, slogan, packaging, visual design and so on [6]. First of all, in order to ensure the 
product's foreign cultural communication target, the design of museum cultural and creative products must be based on systematic and standardized design principles, and establish clear visual images in each link to strengthen the symbolic features of the products. Secondly, according to the product characteristics and technical limitations, we should also scientifically expand the development of cultural elements, effectively update the product image systematically, and enhance the influence of cultural communication.

\section{DESIGN METHOD OF CULTURAL AND CREATIVE PRODUCTS IN JIUJIANG MUSEUM}

The design of cultural and creative products should be rooted in the characteristic culture of museum collections, flexibly apply creative thinking and design methods, and enhance the functionality of cultural and creative products on the basis of reflecting the cultural connotation of museum collections. At the same time, cultural and creative products should become a new carrier of museum cultural information, which can close the communication with the public and make the public focus on the understanding of cultural information. Specifically, the cultural and creative product design of Jiujiang Museum includes the following methods.

\subsection{Skin design}

Skin design is a method of graphic design, which directly applies patterns, textures and symbols to the appearance of products as decoration, thus creating unique visual effects. In the process of designing and developing cultural and creative products, we should pay attention to the selection and extraction of elements in the museum, and innovate the material technology to effectively enhance the novelty of products. At present, most of the cultural and creative products of Jiujiang Museum use printing and stickers, which are characterized by simple product design, short development cycle and low cost. The disadvantage is that some products are relatively low in manufacturability and cannot meet the aesthetic needs of consumers.

\subsection{Skeleton design}

Skeleton design usually extracts the modeling elements and cultural elements of the collection, and combines the functionality of cultural and creative products to carry out the design. Compared with the skin design, skeleton design pays more attention to the deformation of the original shape of elements, highlighting the connotation of the original cultural elements and reflecting the practical significance of cultural and creative products through the expressions of simplification, abstraction and exaggeration [7]. For example, the key chain with the inscription of "Shou" designed by Jiujiang Museum makes full use of the skeleton design method, taking the inscription of "Shou" in Qing Dynasty in Yanshui Pavilion as the prototype, adopting the ancient Chinese window lattice structure as the overall image of the key chain, and matching with blue-and-white lotus pattern porcelain pieces, which not only embodies the characteristics of cultural relics, but also makes cultural and creative products have good practical functions.

\subsection{Implication design}

In the process of designing cultural and creative products in museums, we should give deeper meaning to the products from the perspective of consumers' perception, based on the basic practical functions of the products, so that cultural and creative products can become cultural communication media. Therefore, we should fully consider the multicultural connotation of the museum and be good at excavating the intrinsic meaning of the collection. After fully understanding the cultural connotation, we should change the traditional design thinking and enhance the connotation expression of cultural and creative products. Thereby making the products have higher cultural value and aesthetic significance. Implication design is a high-level design method of cultural and creative products, which mainly separates elements from symbols, not simply repeating styles, but focusing on the core connotation and aesthetic value of cultural elements, and enhancing consumers' cultural character through subtle influence. This design method combines cultural elements with emotional expression, and has the characteristics of story and emotion. When the audience deeply experiences and feels, they will find the unique charm of the product and feel the image beauty of the product more.

\subsection{Deconstructive design}

Deconstructive design is the expression of deconstructive philosophy, which develops artistic design in a new way of thinking. Deconstruction is the decomposition and reorganization of existing relationships and structures, while deconstruction of thinking can often show design ideas and create unique and novel design works. The application of deconstruction in the design of cultural and creative products in museums can deconstruct the meaning of cultural information, combine the function of products with social and cultural atmosphere, and endow cultural and creative products with new connotations [8]. At the same time, funny elements can break the traditional structure and logical relationship, enhance the expression of product meaning, and make it glow with different styles. 


\subsection{Serialization design}

At present, in order to adapt to the development of the times, the museum has gradually changed the traditional academic work style into a more cordial look. At the same time, in order to realize the innovation of the museum in all aspects, various cultural and creative products have been developed and launched, which has promoted the further development of the museum. The design of cultural and creative products should be scientifically innovated, the public demand should be deeply tapped, and the audience range of products should be further expanded. Serialization design refers to a variety of products derived from a theme through changes in form, color, function and materials, each item is unique, and the product combination can express rich cultural connotations [9]. Serialization design can diversify theme elements, form museum brand effect and effectively attract consumers' desire to buy. In addition, serialized products can continuously optimize the product structure and function, which has more advantages than a single product and can meet the diversified needs of the public. For example, the "Clay Tea Cup" designed by Jiujiang Museum can be expanded into a series of cultural products. Starting from the layout themes of the museum buildings such as "Nine Schools of Clouds", "Xunyang Culture Context" and "Academy Millennium", a series of ceramic tea cups with patterns can better serve the purpose of museum culture propaganda.

\section{THE DEVELOPMENT VALUE OF CULTURAL AND CREATIVE PRODUCTS IN JIUJIANG MUSEUM}

\subsection{Meet the Development Needs of the Museum Itself}

Under the development background of today's era, the development of museums is facing many challenges, not only shouldering greater competitive pressure, but also the implementation of the free opening policy requires museums to change their management mode and assume greater social responsibilities. At present, the issue of working capital has become a key research issue for museums to achieve sustainable development. To achieve good development, museums must ensure the quality of cultural communication and social education. However, through analysis and development, most museums have certain operational limitations, and cultural communication cannot achieve the expected results. Cultural and creative products are important means for museums to carry out cultural communication. They can effectively spread the history of museum development and collection culture to the public, and are the best tools to publicize museum culture [10]. At the same time, since its establishment in 1978, Jiujiang Museum has always taken public service as its purpose and assumed the responsibility of serving the public. Social education is one of the important functions of Jiujiang Museum. By developing various cultural and creative products, social education activities can be promoted. At the same time, Jiujiang Museum also has the basic function of cultural relics exhibition. Museum cultural and creative products are the extension of exhibition education and comprehensive services, which can reflect the cultural elements of the collection through different products. With the promotion of cultural and creative products, it can further attract public attention and meet the development needs of the museum itself.

\subsection{Conducive to Promoting the Development of Cultural and Creative Products Industry}

Cultural and creative industries play a significant role in promoting economic development. Local governments and relevant departments have formulated and implemented a series of strategies to promote the development of cultural and creative industries, encourage museums to carry out activities related to cultural and creative industries, raise funds through various channels, and constantly improve museum infrastructure. Under the protection of intellectual property rights, cultural and creative industries can effectively improve the cultural level of the public, create considerable educational effects, and then give full play to the social benefits of museums [11]. With the successful operation of cultural and creative industry of Jiujiang Museum, the potential resources of the museum have been effectively developed, which has realized the income of economic benefits and provided a strong impetus for the further development of the museum.

\subsection{Promote the Image Innovation of the Museum}

With the deepening of the reform, the professional academic status of museums has been continuously improved, and its role has also changed greatly. In the past, museums focused on exhibition of collections. But now most museums have turned their work direction to meet the needs of the public, and gradually changed from the serious atmosphere of the past to the friendly direction. At present, Jiujiang Museum has expanded its functions in the display and collection of cultural relics, paying more attention to the public's cultural needs and emotional experience, and providing more interactive opportunities for the public. Under the influence of this transformation and development, the continuous innovation of museum cultural and creative products will develop the brand effect on the basis of the original cultural functions, which can promote the innovation of the museum image. 


\section{CONCLUSION}

To sum up, museum cultural and creative products, as a form of cultural exchange in the new era, can further narrow the distance with tourists and meet the diverse needs of audiences. Jiujiang Museum, as a comprehensive museum in the city, should give full play to the functions of public education and cultural communication, vigorously develop cultural and creative industries, constantly enrich the design forms of cultural and creative products, enhance the cultural connotation of products, provide richer spiritual guidance for the masses, and then promote the sustainable development of museums.

\section{ACKNOWLEDGMENTS}

I deeply appreciate Assoc. Prof. Dr. Rosjana Chandhasa of Suan Sunandha Rajabhat University for her guidance and encouragement to this paper.

\section{REFERENCES}

[1] Su Dan, Zheng Cheng.Research on the Design of Museum Cultural and Creative Products under the Cultural Confidence Wave[J].Industrial Design, 2021(4):55-56.

[2] Wang Ying.Research on the Differential Design Strategy of Museum Cultural and Creative Products Based on Brand Image System[J].Art Panorama,2020(3):106-107.

[3] Liu Xiaoyi.Research on Visual Design Elements of Museum Cultural and Creative Products[J].China National Exhibition,2021(16):199-201.

[4] Xiong Hongping.Research on the Development and Design of Cultural and Creative Products Based on Museum Resources[J].Young,2021(3): 200.

[5] Guo Wei.Exploration and Thinking on the Design Method of Museum Cultural and Creative Products[J].Identification and Appreciation to Cultural Relics,2020(7): 146-147.

[6] Zhu Mingsen.Research on Cultural and Creative Product Design of Museum[J].Identification and Appreciation to Cultural Relics,2020(5):127-129.

[7] Zhang Yin.Analysis of Innovative Ideas of Museum Cultural and Creative Product Development and Design[J].Divineland,2020(7): 13,15 .

[8] Sun Yu.Research on Product Carrier and Characteristics of Museum Cultural and Creative Design[J].The Journal Of Fashion Design And Engineering,2020(2):6-12.
[9] Ouyang Hua, Zhang Lili.Research on Creative Design of Museum Cultural Products[J].Packaging World,2017(2):101-103.

[10] Wang Ying.Brand Image Design of Museum Cultural and Creative Products[J].Design,2018(14): 139-141.

[11] Han Yueyue.Research on the Innovative Thought of Museum Cultural and Creative Product Development and Design[J]. Divineland, 2021(18): 38-39. 